\title{
The relation between sodium chloride concentration in drinking water and egg-shell damage
}

\author{
BY DERICK BALNAVE AND ISRAEL YOSELEWITZ \\ Department of Animal Husbandry, University of Sydney, Werombi Road, Camden, \\ NSW 2570, Australia
}

(Received 12 March 1987-Accepted 22 June 1987)

\begin{abstract}
1. A significant linear increase in egg-shell defects from 60-week-old laying hens, and corresponding significant linear decreases in various egg-shell-quality measurements, were observed in response to increasing concentrations of sodium chloride in the drinking water, to the maximum concentration of $600 \mathrm{mg} / \mathrm{l}$ used in the present study.

2. The incidence of damaged egg shells was increased 3-fold by including $\mathrm{NaCl}$ in the drinking water at a concentration of $600 \mathrm{mg} / \mathrm{l}$.

3. Shell defects declined when birds were placed on normal water for 5 weeks but were still $1 \cdot 4$ - to $2 \cdot 1$-fold greater than control values.

4. After an induced rest from lay on normal water, shell defects were still 1.3- to $3 \cdot 2$-fold greater in birds which had previously received the $\mathrm{NaCl}$ in the drinking water.

5. The increased incidence of shell damage was not related to decreased food intake or increased egg weight or production.
\end{abstract}

Recent studies (Balnave \& Scott, 1986) have shown that adding any one of a range of mineral salts to the drinking water of laying hens increases the incidence of broken and cracked eggs. The concentrations of the salts used were similar to those observed in some underground water supplies in New South Wales and the intakes of the mineral ions from the water were low compared with intakes from the diet. The chloride salts of sodium and potassium were particularly effective when given for 6 weeks and the numbers of defective shells laid by commercial pullets approximately doubled during this short time. What was particularly disturbing was that the birds continued to produce large numbers of damaged shells over a subsequent 4-week period when the mineral supplements were excluded from the drinking water. This response suggests that calcium metabolism, and the bird's ability to produce normal egg shells, was permanently affected by the presence of these mineral salts in the drinking water.

Egg producers in many countries use underground water supplies as sources of drinking water for table-egg- and fertile-egg-producing poultry flocks. These water sources are usually high in dissolved salts of which $\mathrm{NaCl}$ is a major constituent. The present study was carried out to examine the dose-response relation between the $\mathrm{NaCl}$ concentration in the drinking water and egg-shell quality and the incidence of shell damage in a commercial table-egg flock.

\section{MATERIALS AND METHODS}

Four replicates, each of ninety-five 60-week-old laying hens at the end of their laying year, were allocated to each experimental treatment in September 1986. Before and during the experiment all birds were maintained on a proprietary laying mash, the calculated composition of which was given previously (Balnave \& Scott, 1986). Municipal town water containing on average $2.4 \mathrm{mg} \mathrm{Na}$ and $<1 \mathrm{mg} \mathrm{Cl} / 1$ was used as the source of drinking water.

Birds were given free access to food and to water containing either $0,200,400$ or 600 
mg added $\mathrm{NaCl} / 1$. The housing of the birds and the management of the experiment were carried out as described previously (Balnave \& Scott, 1986) except that the experimental treatments were applied for a 5-week period. After this time the $\mathrm{NaCl}$ supplements were stopped and the birds were maintained on municipal town water for a further 5 weeks. The birds were then rested from lay by feeding whole barley for 2 weeks followed by whole wheat for 2 weeks. This effectively reduced the flock egg production to zero for $10 \mathrm{~d}$. The birds were then re-fed the proprietary laying mash and 5 weeks after returning to lay (week 20,80 weeks of age) the incidence of shell damage was again determined over a $7 \mathrm{~d}$ period. Each treatment replicate was treated as an experimental unit with food intake, egg production, numbers of damaged shells and shell-quality measurements being recorded for the complete group. Before the rest from lay, maximum daily ambient temperatures in the layer shed were normally less than $26^{\circ}$, but after returning to lay maximum daily temperatures were consistently above $32^{\circ}$ for the final 5 weeks of the experiment.

The eggs were collected and inspected manually. The numbers of cracked, broken and soft-shelled eggs were determined on the $2 \mathrm{~d}$ before the commencement of the experiment and on each day of weeks 1 and 20. Otherwise, shell damage was measured every $7 \mathrm{~d}$ after allowing the eggs from three consecutive days to accumulate on the cage fronts. Records of food and water intakes and egg production were made for weeks 1-5 and weeks 6-10. All the eggs collected during the final $2 \mathrm{~d}$ of weeks 5 and 10 , and on the last day of week 20, were used for shell-quality measurements. Egg-shell breaking strength was measured as the shell resistance to increasing pressure applied at the broad end of the shell and egg-shell thickness was measured, using an Ames thickness micrometer gauge, on three pieces of shell from the equator of each egg. The absolute shell weight, percentage shell weight and the shell weight per unit surface area were measured as described by Curtis et al. (1985).

Statistical analyses were carried out as described by Steel \& Torrie (1980) using a splitplot analysis of variance with time as the split-plot factor. Linear regression equations relating the incidence of egg-shell damage and the various measures of egg-shell quality to the $\mathrm{NaCl}$ concentration in the drinking water and the egg-shell-quality measurements to the incidence of shell damage during the final $2 \mathrm{~d}$ of $\mathrm{NaCl}$ supplementation were also developed.

\section{RESULTS}

As in previous studies the incidence of soft-shelled eggs was low $(<0 \cdot 25 \%)$ and shell defects reflected the incidence of broken and cracked eggs. The results shown in Fig. 1 indicate the pattern of production of damaged shells during weeks 1-10 of the experiment. The overall mean incidence of damaged egg shells and other production characteristics during weeks $1-5$ and 6-10, and egg-shell-quality measurements made during weeks 5, 10 and 20 are shown in Tables 1 and 2 respectively.

During weeks 1-5, when the $\mathrm{NaCl}$ supplements were added to the drinking water, the numbers of damaged egg shells increased significantly $(P<0.001)$ in direct proportion to the concentration of $\mathrm{NaCl}$ (Fig. 1, Table 1). This response was rapid, being evident within $2 \mathrm{~d}$ of the introduction of the $\mathrm{NaCl}$ supplements. The mean (with range, $n 4$ ) percentage of eggs showing shell damage during weeks $1-5$ on treatments containing $0,200,400$ and $600 \mathrm{mg} \mathrm{NaCl} / 1$ respectively were $6.5(6.1-6.9), 10.4(8.9-11.2), 14.2(13.4-15.0)$ and 18.9 $(16 \cdot 3-21 \cdot 9)$. The relation between mean egg-shell damage (ESD) and $\mathrm{NaCl}$ concentration in the drinking water $(X)$ during weeks 1-5 was described by

$$
\mathrm{ESD}=0.021(\text { SE 0.0014) } X+6.32, r 0.97(P<0.001) \text {. }
$$

The similarity of this equation to that obtained using the values for the final $2 \mathrm{~d}$ of $\mathrm{NaCl}$ 


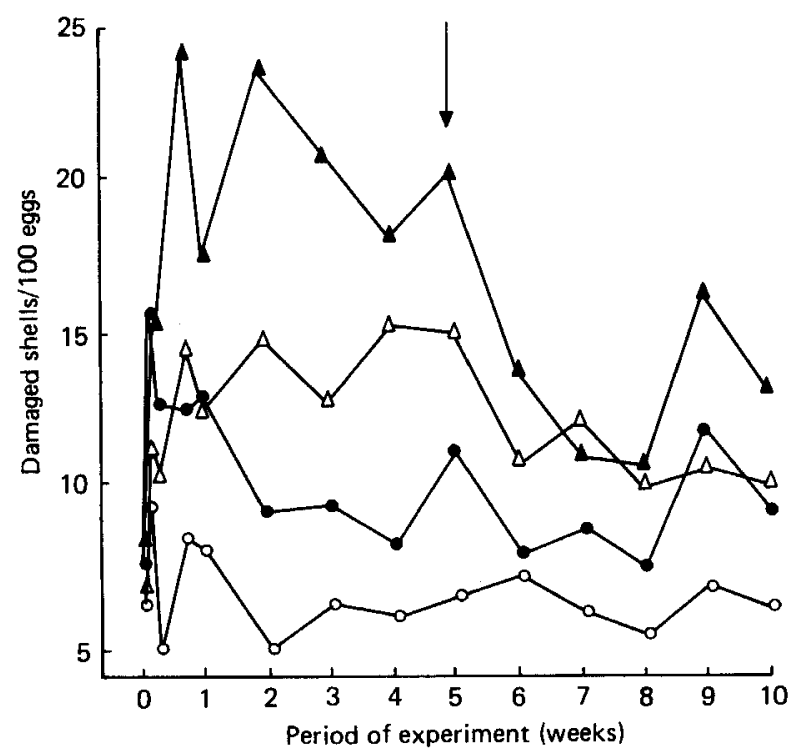

Fig. 1. Production of eggs with damaged shells from hens receiving $0(O), 200(\bigcirc), 400(\triangle)$, and 600 (A) $\mathrm{mg}$ sodium chloride $/ 1$ drinking water during weeks $1-5 . \downarrow, \mathrm{NaCl}$ supplements end.

Table 1. Mean egg-shell damage and production variables during the periods when sodium chloride was added to (weeks 1-5) and removed from (weeks 6-10) the drinking water

\begin{tabular}{|c|c|c|c|c|c|}
\hline $\begin{array}{l}\text { Supplement } \\
\text { of } \mathrm{NaCl} \\
(\mathrm{mg} / \mathrm{l})\end{array}$ & $\begin{array}{l}\text { Period of } \\
\text { measurement } \\
\text { (weeks) }\end{array}$ & $\begin{array}{c}\text { Damaged } \\
\text { shells } \\
\text { (/100 eggs) }\end{array}$ & $\begin{array}{c}\text { Egg } \\
\text { production } \\
\text { (/bird day) }\end{array}$ & $\begin{array}{l}\text { Food } \\
\text { intake } \\
(\mathrm{g} / \mathrm{d})\end{array}$ & $\begin{array}{l}\text { Water } \\
\text { intake } \\
(\mathrm{ml} / \mathrm{d})\end{array}$ \\
\hline 0 & $1-5$ & $6 \cdot 5$ & 0.694 & $122 \cdot 5$ & 277 \\
\hline 200 & $1-5$ & $10 \cdot 4$ & 0.663 & $123 \cdot 3$ & 286 \\
\hline 400 & $1-5$ & $14 \cdot 2$ & 0.656 & $121 \cdot 3$ & 268 \\
\hline 600 & $1-5$ & 18.9 & 0.681 & 123.5 & 266 \\
\hline 0 & $6-10$ & $6 \cdot 3$ & 0.624 & $127 \cdot 3$ & 240 \\
\hline 200 & $6-10$ & $9 \cdot 1$ & $0 \cdot 628$ & $127 \cdot 2$ & 251 \\
\hline 400 & $6-10$ & $10 \cdot 5$ & 0.623 & 121.5 & 243 \\
\hline 600 & $6-10$ & $13 \cdot 1$ & 0.625 & $124 \cdot 0$ & 250 \\
\hline \multicolumn{6}{|c|}{ SED and level of significance } \\
\hline $\mathrm{NaCl}$ & & $0 \cdot 36^{* * *}$ & 1.39 & 1.95 & $1.7^{*}$ \\
\hline Time & & $0 \cdot 60 * * *$ & $0.95^{* * *}$ & $1.07^{*}$ & $2 \cdot 0^{* * *}$ \\
\hline $\mathrm{NaCl} \times$ time & & $0.92^{*}$ & 1.93 & $2 \cdot 46$ & $3 \cdot 3$ \\
\hline
\end{tabular}

SED, standard error of difference. ${ }^{*} P<0.05 .{ }^{* * *} P<0.001$.

supplementation (Table 3) reflects the rapid increase in shell damage observed on the introduction of the $\mathrm{NaCl}$ to the drinking water (Fig. 1).

The incidence of damaged shells was reduced once the supplements of salt were excluded from the drinking water during weeks 6-10. Nevertheless, the incidence was still significantly $(P<0.001)$ higher than that of controls in all treatments. The mean (with range, $n 4$ ) percentage of eggs showing shell damage during weeks 6-10 from birds previously receiving $0,200,400$ and $600 \mathrm{mg} \mathrm{NaCl} / \mathrm{l}$ respectively were $6 \cdot 3(5 \cdot 5-7 \cdot 1), 9 \cdot 1$ $(7 \cdot 8-10 \cdot 0), 10 \cdot 5(8 \cdot 3-12 \cdot 3)$ and $13 \cdot 1(11 \cdot 5-14 \cdot 6)$. Therefore improvements were much greater, 


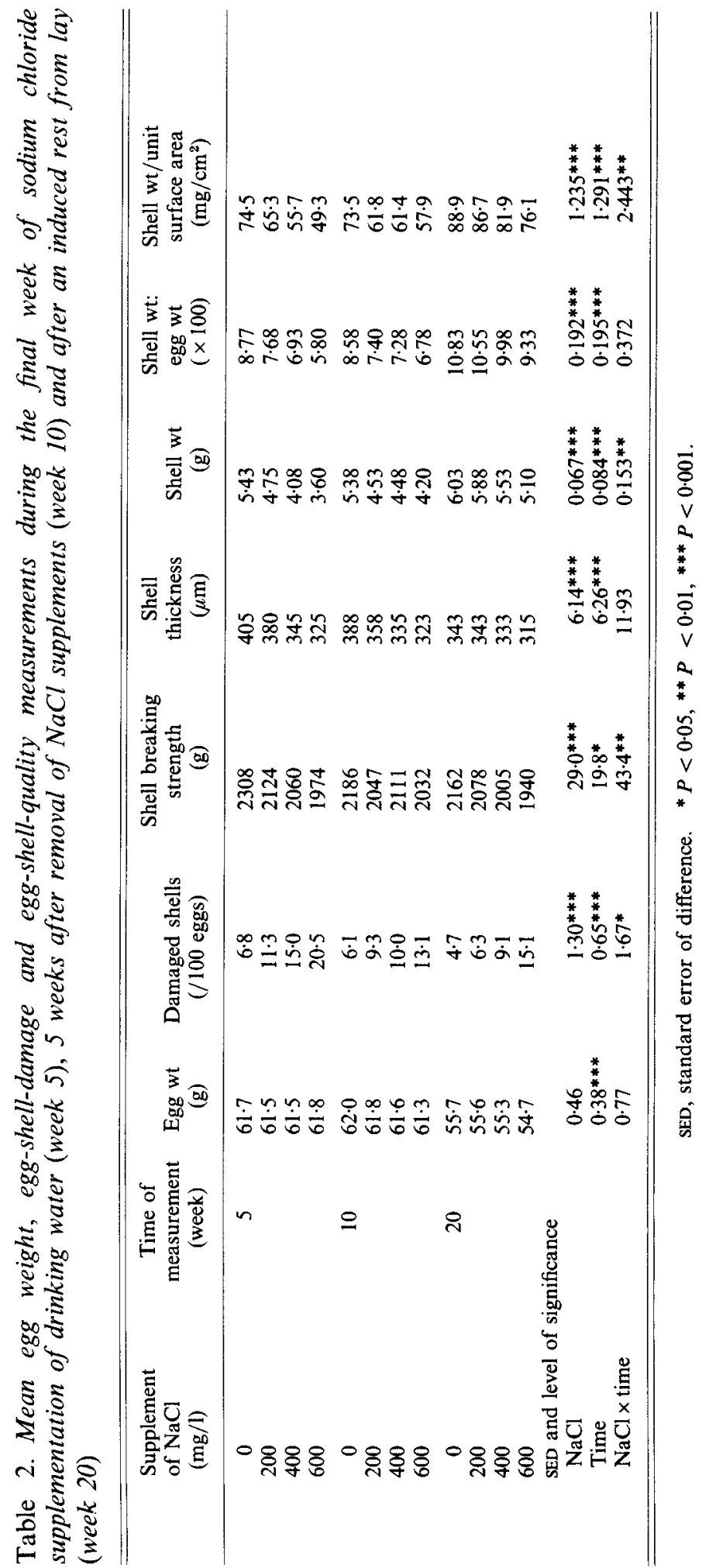


Table 3. Linear regression equations relating shell damage and egg-shell-quality measurements (Y) during the final $2 d$ of sodium chloride supplementation to the concentration $(\mathrm{mg} / \mathrm{l})$ of $\mathrm{NaCl}$ in the drinking water $(\mathrm{X})$

\begin{tabular}{|c|c|c|c|c|c|}
\hline \multirow{3}{*}{$\begin{array}{l}\text { Egg-shell } \\
\text { measurement } \\
(V)\end{array}$} & \multicolumn{4}{|c|}{$Y=B(X)+A$} & \multirow{3}{*}{$\begin{array}{c}\text { Statistical } \\
\text { significance }\end{array}$} \\
\hline & \multicolumn{2}{|c|}{$B$} & \multirow[b]{2}{*}{$A$} & \multirow[b]{2}{*}{$r$} & \\
\hline & Mean & SE & & & \\
\hline $\begin{array}{l}\text { Shell damage (/100 } \\
\text { eggs) }\end{array}$ & 0.022 & 0.0020 & 6.67 & 0.95 & $* * *$ \\
\hline $\begin{array}{l}\text { Shell breaking strength } \\
\text { (g) }\end{array}$ & -0.58 & $0 \cdot 100$ & 2283 & -0.84 & $* * *$ \\
\hline Shell thickness $(\mu \mathrm{m})$ & -5.87 & 0.850 & $442 \cdot 4$ & -0.88 & $* * *$ \\
\hline Shell wt (g) & -0.003 & 0.0003 & $5 \cdot 39$ & -0.93 & $* * *$ \\
\hline Shell wt (g): egg wt (g) & -0.005 & 0.0008 & 8.75 & -0.84 & $* * *$ \\
\hline $\begin{array}{l}\text { Shell wt } / \text { unit surface } \\
\text { area }\left(\mathrm{mg} / \mathrm{cm}^{2}\right)\end{array}$ & -0.043 & 0.0051 & 73.95 & -0.91 & $* * *$ \\
\hline
\end{tabular}

*** $P<0.001$.

although the incidence of shell damage was still higher, in birds previously receiving the higher concentrations of $\mathrm{NaCl}$.

Even after an induced rest from lay on normal water the incidence of damaged egg shells (week 20) was still 1-3- to 3-2-fold greater in birds which had received the $\mathrm{NaCl}$ supplements in the drinking water during weeks $1-5$ (Table 2). The rates of egg production (per bird day) during week 20 were $0.713,0.765,0.769$ and 0.753 at $600,400,200$ and $0 \mathrm{~g} \mathrm{NaCl} / 1$ respectively.

The significant $(P<0.001)$ increases in egg-shell damage during weeks $1-5$ observed with increasing $\mathrm{NaCl}$ supplementation of the drinking water were reflected in corresponding significant $(P<0.001)$ reductions in various measures of egg-shell quality (Table 2$)$. The very highly significant $(P<0.001)$ relations between the various measures of egg-shell quality and the $\mathrm{NaCl}$ concentration in the drinking water during the final $2 \mathrm{~d}$ of $\mathrm{NaCl}$ supplementation are shown in Table 3.

In addition, all egg-shell-quality measurements were very highly significantly related to the degree of shell damage, the respective correlation coefficients being for shell breaking strength $(-0.75)$, shell thickness $(-0.88)$, shell weight $(-0.90)$, shell weight:egg weight $(-0.84)$ and shell weight per unit surface area $(-0.85)$. There was no significant relation between egg weight and shell damage $(r 0.11)$ or between egg weight and $\mathrm{NaCl}$ concentration in the drinking water $(r$ 0.03). During weeks 6-10, when birds received normal water, the egg-quality measures were still significantly poorer that those of controls on all treatments (Table 2). Similar trends were observed even after an induced rest from lay (Table 2) by which time birds had been on normal water for 15 weeks. The increase in shell weight which occurred after the rest from lay, combined with the reduced egg weight which occurred at this time in response to the high ambient temperatures, influenced the absolute shell weight:egg weight ratio and the shell weight per unit surface area values.

Food intake and egg production were not significantly affected by $\mathrm{NaCl}$ treatment (Table 1). The consumption of drinking water was significantly $(P<0.05)$ influenced by $\mathrm{NaCl}$ treatment but quantitative differences between treatments were small. 


\section{DISCUSSION}

It is generally recognized that about $6-8 \%$ of all eggs produced by laying hens are downgraded primarily because of shell damage (The Eggs Authority, 1978; Hamilton et al. 1979). Therefore, in the present study, the level of shell damage in eggs from the control birds receiving no additional $\mathrm{NaCl}$ in the drinking water was within expected limits.

$\mathrm{NaCl}$ concentrations ranging from 0 to $600 \mathrm{mg} / \mathrm{l}$ were examined in the present work. although underground sources of water used by poultry producers in Australia often contain much higher concentrations of $\mathrm{NaCl}$ (E. E. Best, personal communication). Nevertheless, a significant linear relation was observed between the incidence of shell damage and the $\mathrm{NaCl}$ concentration in the drinking water. Previous studies found that the incidence of shell defects was approximately doubled by including $\mathrm{NaCl}$ in the drinking water for 6 weeks at a concentration of $250 \mathrm{mg} / 1$ (Balnave \& Scott, 1986). In the present 5 week study a 3-fold increase in shell-damaged eggs was observed at a $\mathrm{NaCl}$ concentration of $600 \mathrm{mg} / 1$.

The report of Austic (1984) suggests that $\mathrm{Cl}^{-}$is the most likely factor responsible for the effects noted in the present study but previous comparisons of $\mathrm{NaCl}, \mathrm{KCl}$ and calcium chloride supplements in drinking water question this supposition (Balnave \& Scott, 1986). Since $\mathrm{Cl}^{-}$was added as the $\mathrm{Na}$ salt no change in the overall electrolyte balance, as defined by Mongin \& Sauveur (1977) and Mongin (1981), occurred which would have influenced acid-base balance through an imbalanced intake of $\mathrm{Cl}^{-}$.

The increased shell damage resulting from $\mathrm{NaCl}$ supplementation of the drinking water was associated with reductions in various measurements of shell quality. This contrasts with previous observations (Balnave \& Scott, 1986) where egg-quality measurements were limited to normal eggs within a specific weight range. In the present study significant linear relations were observed between various measurements of egg-shell quality and the $\mathrm{NaCl}$ concentration in the drinking water.

Although the incidence of shell damage declined when birds were given normal drinking water for 5 weeks it remained higher than control values and was proportional to the concentration of $\mathrm{NaCl}$ originally added to the drinking water. As in earlier work (Balnave $\&$ Scott, 1986) the improvement in shell quality which normally occurs after a rest from lay was not evident in the $\mathrm{NaCl}$-treated birds in the present study, although at the time of the final egg-quality measurements the birds had been drinking normal water for 15 weeks. This suggests that the $\mathrm{NaCl}$ intake from the drinking water was influencing Ca metabolism in such a way as to affect permanently the ability of some birds to produce normal egg shells. If so, the supply of $\mathrm{NaCl}$-contaminated drinking water to young laying pullets, even for short periods of time, could have long-term economic consequences for poultry producers.

As with previous studies the increased incidence of shell damage was not related to decreased food (i.e. Ca) intake or increased egg weight or production. As with the earlier studies the intakes of $\mathrm{Na}^{+}$and $\mathrm{Cl}^{-}$from the drinking water were low compared with intakes from the diet, ranging from 10 to $30 \%$ of the total intake with the 200 and $600 \mathrm{mg} / 1$ supplements.

The present study was supported by the Poultry Research Council and the Poultry Husbandry Research Foundation. Statistical advice was provided by Ms. A. C. Kirby, Department of Agricultural Genetics and Biometry, University of Sydney 


\section{REFERENCES}

Austic, R. E. (1984). Poultry Science 63, 1773-1777.

Balnave, D. \& Scott, T. (1986). Nutrition Reports International 34, 29-34.

Curtis, P. A., Gardner, F. A. \& Mellor, D. B. (1985). Poultry Science 64, 297-301.

Hamilton, R. M. G., Hollands, K. G., Voisey, P. W. \& Grunder, A. A. (1979). World's Poultry Science Journal 35, 177-190.

Mongin, P. (1981). In Recent Advances in Animal Nutrition, pp. 109-119 [W. Haresign, editor]. London: Butterworths.

Mongin, P. \& Sauveur, B. (1977). In Growth and Poultry Meat Production, pp. 235-247 [K. N. Boorman and B. J. Wilson, editors]. Edinburgh: British Poultry Science.

Steele, R. G. D. \& Torrie, J. H. (1980). Principles and Procedures of Statistics. Kogakusha, Tokyo: McGrawHill.

The Eggs Authority (1978). Technical Bulletin no. 2. Tunbridge Wells, Kent: The Eggs Authority, UK. 